\title{
FATORES QUE FAVORECEM A REINCIDÊNCIA CRIMINAL A LUZ DA ANÁLISE FUNCIONAL
}

\section{FACTORS FAVORING THE RECIDIVISM IN THE LIGHT OF FUNCTIONAL ANALYSIS}

\author{
Verena Souza Souło*, Mariana São Thiago Bezerra de Menezes** \\ Autora para correspondência: Verena Souza Souto - verena.souto@gmail.com \\ * Mestranda em Tecnologias em Saúde pela Escola Bahiana de Medicina. \\ Psicóloga nas Unidades Móveis de Acolhimento à Mulheres em situação de violência doméstica. \\ **Mestre em Psicologia Experimental - Análise do Comportamento pela PUC/SP. Psicóloga e professora na \\ graduação do curso de psicologia da Faculdade da Cidade do Salvador (FCS), da Faculdade de Ciências \\ e Tecnologia (FTC) e do Centro Universitário Unijorge
}

\section{R E S U M O}

Objetivos: A tentativa de obter comportamentos socialmente adequados num ambiente em que há privação de reforçadores apropriados é bastante evidente no sistema carcerário atual e torna o índice de reincidência elevado. Por esse motivo o presente trabalho buscou fazer uma análise das contingências da vida de um detento que podem se relacionar à reincidência criminal, pois o tempo limitado de contato com o sujeito e a multideterminação do comportamento não permite ter certeza de quais variáveis independentes podem ser responsáveis pela reincidência. Método: Foi feito um estudo descritivo do histórico de um sujeito apenado reincidente da Penitenciária Lemos de Brito em Salvador-BA, utilizando como instrumento de coleta de dados a entrevista aberta e a análise funcional para interpretação dos dados. Resultados/Discussão: A partir do presente estudo, pôde-se pensar que o Sistema Prisional tem dificuldade para dispor de meios eficazes para a ressocialização do detento, não o preparando de modo real para sua reinserção na sociedade tendo como principal consequência a reincidência criminal. Considerações finais: Torna-se necessário pensar em estratégias de investimento no tratamento penal e no acompanhamento dos egressos do sistema prisional e pensar em possibilidades de construção de políticas públicas, considerando, dentre outras medidas, a atenção psicossocial.

Palavras-chave: reincidência; behaviorismo; coerção; prisões. 
Objectives: Attempting to obtain socially appropriate behaviors in an environment where there is deprivation of appropriate reinforcers is very evident in the current prison system and makes the high recidivism rate hight. Therefore this work seeks to analyze the contingencies involved in the history of recidivism of an individual, because the limited time of contact with the subject and the multiplicity of behavior does not make sure about the use of independent variables of recidivism. Methods: Through the historical descriptive study of this subject recidivist convict Lemos Brito Penitentiary in Salvador$B A$, using as an instrument to collect data open interview and functional analysis as a method of data evaluation. Results/Discussion: From this study it is possible to conclude that the prison system has difficulty to have effective means for the rehabilitation of the detainee, not prepared in a real way for their integration into society with the main effect of recidivism. Conclusion: It is necessary to consider investment strategies in the criminal treatment and monitoring of former convicts and think of public policy building possibilities, considering, among other measures, the psychosocial care.

Keywords: relapse; behaviorism; coercion; prisons. 


\section{INTRODUÇÃO}

Para cumprir o objetivo de manter a ordem, a sociedade tende a apresentar medidas coercitivas que possibilitem solucionar problemas que possam ameaçar a integridade social. A prisão se apresenta como uma estratégia que visa ressocializar pessoas condenadas ao cumprimento de pena determinado em lei. No entanto, da forma como a sociedade se estrutura observa-se um problema no sistema carcerário: as prisões são aplicadas apenas com o objetivo de punir os comportamentos inadequados.

O isolamento com o intuito de levar a uma reflexão a respeito do delito cometido não pode ser considerado uma forma eficaz de socialização. Além disso, o Sistema Prisional Brasileiro não apenas isola, mas expõe os detentos a condições subumanas e, embora previsto, nem sempre os submetem a atividades que possam auxiliar na reintegração do indivíduo à sociedade. Parece que o intuito é apenas deixá-lo à margem para evitar que possa voltar a pôr em risco a ordem tão pretensamente garantida.

Os dados mais recentes do Sistema Nacional de Informação Penitenciária (INFOPEN) do Departamento Penitenciário Nacional sobre reintegração social datam de junho de 2014. De acordo com ○ INFOPEN, a população carcerária era de 607.731 pessoas nesse período, e destas, apenas $16 \%$ estavam inseridas em políticas de reintegração social relativas a trabalho, renda e qualificação profissional'.

As informações sobre a reincidência criminal e sobre as práticas de ressocialização são escassas. O Instituto de Pesquisa Econômica Aplicada (IPEA) realizou a primeira pesquisa com dados estatísticos sobre esta questão no ano de 2015, com apenas cinco Estados (Paraná, Minas Gerais, Rio de Janeiro, Alagoas e Pernambuco) ${ }^{2}$. E, embora já se tenha alguns outros estudos sobre a reincidência criminal ${ }^{3-6}$, estes ainda são incipientes e a compreensão deste fenômeno, bem como o seu oposto (os programas e possibilidades de ressocialização), são uma necessidade premente, uma vez que a pesquisa social em criminologia no Brasil caminha vagarosamente e a temática da reincidência participa fortemente dessa grave lacuna 5 .
Estima-se que $\circ$ percentual de reincidência no Brasil no ano de 2014 esteja em cerca de $70 \%{ }^{7}$. No sistema prisional brasileiro até junho de 2014 haviam 607.731 detentos, sendo que, de acordo com dados do INFOPEN do Departamento Penitenciário Nacional', esse número cresceu vertiginosamente desde $\circ$ ano de 2002. Dados do departamento supramencionado mostram que nesse ano a população carcerária era de 239.345 apenados, isso denota um crescimento de cerca de $153 \%$ no número de detentos em 12 anos. Importante salientar que a quantidade de vagas disponíveis no sistema era 376.669 , o que deixou um déficit de aproximadamente 231.062 vagas. Ou seja, a própria estrutura física das penitenciárias é insustentável e o sistema prisional brasileiro não tem capacidade suficiente para abrigar o número de presos que mantém.

Vale ressaltar que, de acordo com dados do departamento supramencionado a população carcerária brasileira tem como perfil: homens (75\%), adultos jovens entre 18 e 29 anos (56\%), negros $(67 \%)$, solteiros $(57 \%)$, com escolaridade de ensino fundamental incompleto $(53 \%)$ e que cometeram crimes do tipo tráfico, roubo ou furto (59\%). Esses dados podem denotar o retrato de uma sociedade desigual desde a sua constituição'. Uma vez que, a sociedade brasileira ainda se mantém pelas disparidades sociais vertiginosas e pela pobreza massificada, que juntas alimentam o crescimento da violência criminal transformada em principal flagelo das grandes cidades ${ }^{8}$.

Diante de tal desigualdade social, a prisão tem sido usada, em grande medida, para administrar, tanto pela via da correção quanto pela via da neutralização, as classes tidas como perigosas, ou seja, os indivíduos criminosos ${ }^{9}$. Nesse aspecto, cabe destacar que as prisões funcionam como 'aspirador social' para limpar as escórias das transformações econômicas em curso: os infratores ocasionais, os jovens autores de pequenos furtos, os desempregados e os sem-teto; os toxicômanos e toda ordem de excluídos sociais deixados de lado pela proteção social ${ }^{10}$.

Ao falar de criminalidade, vale ressaltar que este é um fenômeno complexo e sujeito a inúmeras determinações e o tratamento penal do crime é longo e multifacetado. Portanto, para entender a 
criminalidade, é importante compreender o papel da criminalização da pobreza, da demonização das drogas, da espetacularização da violência, da criação da figura do inimigo interno e da funcionalidade do fracasso da prisão?.

Por isso, é percebida a necessidade de repensar o sistema prisional. Atualmente, o encarceramento como ideal de reabilitação pode ser substituído, em alguns casos, por tipos diferentes de regimes. Isto é, penas alternativas que estão previstas nos termos da Lei de Execução Penal (LEP) ${ }^{11}$ e que deveriam ser adotadas nas prisões para evitar $\circ$ isolamento total e possibilitar a ressocialização dos sujeitos que estão sob os termos da LEP. A medida, em hipóteses como essa, atende precipuamente aos princípios de humanidade e de respeito ao preso, e constitui atitude coerente do poder estatal ${ }^{12}$.

As penas alternativas se apresentam como um tipo de punição mais contingente ao delito cometido. Ou seja, na atual conjuntura não há como rejeitar o encarceramento prisional, mas pode-se fazer uso de uma punição que seja, dentro do possível, mais branda, eficiente, justa e construtiva. Nesse caso, é necessária uma relação funcional (que analisa as condições em que o comportamento ocorreu) entre a emissão do comportamento inadequado e a perda ou ganho de privilégios ${ }^{13}$. Isso torna possível a diminuição de formas brutas de punição e facilita - trabalho na busca pela ampliação e construção de condutas desejáveis sem provocar os efeitos colaterais que a coerção apresenta ${ }^{14}$.

A ideia se mostra interessante, tanto para reinserir estes indivíduos na sociedade quanto para amenizar - problema de superlotação nos presídios. Mas, no geral, as penas alternativas não são efetivadas, pois, mesmo que as prisões tenham projetos de educação e trabalho visando à reintegração futura, estes são tão tímidos que não chegam a adquirir uma importância, de fato, no processo de reabilitação da população carcerária ${ }^{15}$.

Os projetos de trabalho se apresentam como uma maneira importante de ressocialização de um indivíduo aprisionado. No entanto, a forma como ele está organizado dá-lhe apenas a finalidade de enquadramento social dentro do contexto penitenciário com $\circ$ intuito de manter a ordem. Desta maneira, quebrar paradigmas referentes ao trabalho prisional é um desafio posto para a sociedade brasileira na busca da ressocialização do preso e da diminuição das elevadas taxas de reincidência que são parte da realidade prisional ${ }^{16}$.

As tentativas de educação dentro dos presídios também são limitadas, uma vez que nem os conteúdos nem os métodos são adaptados para a população carcerária e isso constitui um grande obstáculo para a aprendizagem. Além disso, vale ressaltar a necessidade de se perceber que a maioria dos detentos viveu fracassos no sistema escolar e que as mesmas metodologias, transpostas para a prisão, estão fadadas a produzir o mesmo resultado ${ }^{17}$.

Em suma, a questão da reincidência pode ser interpretada como um problema de discriminação, tanto quanto um problema derivado da experiência prisional em si. Representa o fracasso do esforço social pela re-socialização dos infratores e a consolidação da sua exclusão. Por isso, a compreensão desse fenômeno e dos programas e possibilidades de ressocialização é uma necessidade salutar ${ }^{5}$.

Dessa maneira, torna-se importante conhecer e compreender as variáveis presentes na história de vida dos sujeitos apenados analisando as contingências do contexto de reincidência criminal, investigando a existência de práticas de reintegração social e averiguando possíveis variáveis controladoras do ato criminal dentro e fora da prisão. Ao conhecer as causas da reincidência criminal é que podemos atuar nas contingências que controlam este comportamento e desenvolver estratégias mais eficazes de reintegração social.

\section{MÉTODOS}

A estratégia de investigação foi uma pesquisa qualitativa cujo propósito de investigação foi do tipo exploratório, assumindo a forma de relato de caso e seu procedimento técnico foi a pesquisa de campo. O presente relato de caso foi feito com somente um detento, no qual foram investigadas algumas variáveis presentes e passadas da história de reincidência criminal do mesmo. Nesse contexto foram realizadas duas entrevistas apenas, por conta 
da disponibilidade do interno em ser entrevistado (no geral, eles apresentaram resistência para serem entrevistados se isso não resultava em benefícios diretos para eles), pela falta de tempo para realização da pesquisa e pelas dificuldades que permeiam o ambiente prisional.

Como critérios de inclusão foram adotados os seguintes: a) o entrevistado foi um apenado do sexo masculino que reincidiu ao menos duas vezes e com idade acima de 30 anos, uma vez que a maioria da população carcerária reincidente está dentro dessa faixa etária, por conta do próprio tempo que leva para cumprir pena e reincidir; b) cumprimento de regime fechado por roubo simples ou qualificado de acordo com o Art. 157 do Código Penal Brasileiro e/ou tráfico de entorpecentes segundo Art. 12 da Lei $6.368 / 76^{18}$. Esse último critério foi selecionado por caracterizar o perfil de em média $50 \%$ da população carcerária do Sistema Prisional da Bahia, por isso o sujeito entrevistado representa uma amostra da população.

A entrevista foi realizada mediante o consentimento voluntário do entrevistado e a assinatura do Termo de Consentimento Esclarecido que garantiu o sigilo e a preservação da identidade do informante, bem como o livre uso dos dados informados pelo entrevistado com finalidade estrita para pesquisa. Além disso, a pesquisa foi desenvolvida após a aprovação do Comitê de Ética da Faculdade de Tecnologia e Ciências de Salvador.

A Instituição envolvida na pesquisa foi a Penitenciária Lemos de Brito localizada no Município de SalvadorBahia. Através dela foi selecionado o detento que se enquadrou no perfil supramencionado e que se dispôs a participar da pesquisa.

Os dados foram coletados por meio de roteiro de entrevista aberta para um melhor detalhamento de questões e formulação mais precisa dos conceitos relacionados $^{19}$. As entrevistas foram feitas no mês de Outubro de 2010.

Como forma de avaliação foi utilizada a análise funcional, que através de contingências passadas, buscou identificar, a partir do relato, a função dos atos criminais cometidos pelo sujeito entrevistado ${ }^{20}$.

\section{RESULTADOS E DISCUSSÃO}

O sujeito da pesquisa chama-se Pedro (Nome fictício para preservar a identidade do entrevistado) e possui 42 anos de idade. Estudou apenas até a primeira série do Ensino Fundamental e saiu de casa aos dezoito anos para trabalhar e morar com uma mulher. Nunca teve um trabalho com carteira assinada. Relatou como exemplos de experiências profissionais "biscates" em serviços variados, tais como: pintura, colocação de gesso, calçamento de pedras portuguesas e teve um carrinho de pipoca na frente de uma escola. Mantém um relacionamento de nove anos com uma mulher e possui um filho de 16 anos, de outra relação, com quem não tem contato.

Seu histórico penal é extenso. As primeiras ocorrências são de pelo menos três prisões em delegacias por brigas no período de três a cinco meses. Sua primeira prisão por condenação judicial foi aos 25 anos por Tráfico de Entorpecentes (Art. 12 do Código Penal Brasileiro) ${ }^{18}$ e cumpriu pena de três anos e oito meses. Ao ser liberado judicialmente por ter cumprido a sua pena foi preso três meses depois por Latrocínio - roubo seguido de morte - (Art. 157 do Código Penal Brasileiro) ${ }^{18}$ e condenado a 27 anos e oito meses, dos quais já cumpriu 13 anos.

A história de vida de Pedro apresentou condições aversivas antecedentes ao delito que possivelmente contribuíram para que fosse colocado pela primeira vez na prisão por condenação judicial: pobreza, baixa escolaridade e ausência de rede de apoio social. A privação de reforçadores positivos (tais como dinheiro, afeto, acesso à educação etc) no ambiente de Pedro tornou-se, nesse caso, uma operação estabelecedora que aumentou a probabilidade da emissão de repostas, como por exemplo, cometer crimes para obter esses reforços dos quais foi privado 20,21 .

Exposto às contingências supramencionadas e as tendo como operações estabelecedoras, Pedro encontrou nas drogas um alívio para as tensões de sua vida (reforçamento negativo) e uma maneira fácil para obtenção de dinheiro (reforçamento positivo), estava posto o estímulo discriminativo que evocaria a resposta aqui identificada como comportamento de interesse: 0 delito ${ }^{20}$. 
Dos três anos e onze meses aos quais foi condenado em seu primeiro julgamento, ganhou três meses de redução de pena, cumprindo três anos e oito meses em Instituições Prisionais. No período de reclusão, apenas trabalhou com serviços gerais por um tempo, mas não foi exposto a nenhuma contingência que pudesse eficazmente ampliar seu repertório para emissão de respostas mais adequadas.

Após cumprir a pena foi judicialmente liberado. Voltou a morar com a família, pois vendeu tudo que possuía para pagar o advogado. Com a perda de sua independência financeira, Pedro teve que dividir um espaço com muitas outras pessoas, já que passou a morar com suas irmãs, sobrinhas e sobrinhos, todos compartilhando o pequeno espaço e os poucos recursos. Durante os três meses que ficou em liberdade tentou de várias formas conseguir um emprego, mas com a baixa escolaridade que possui - e agora com o estigma de ex-detento embora tivesse feito vários "biscates", não conseguiu trabalho estável, conforme narrativa abaixo em relação à reincidência e sentimento de liberdade:

"Um alívio véi. Eu digo "é, vou pra nunca mais, vou arranjar um trabalho e vou trabalhar". Aí pronto, ia aqui, ali, aqui e nada de trabalho, ali, aqui, ali, e nada de trabalho, eu digo que "porra é essa véie!". E agora pra comer? Pra beber? Pra tudo? Que dinheiro é pra tudo, né? Eu digo "é, vou correr atrás que não pode ficar parado não", ganhei esses dias aí."
Mais uma vez Pedro estava exposto a condições aversivas: preconceito por ser ex-detento e a privação de dinheiro (reforçador condicionado generalizado), levando-o a continuar sendo sustentado pela família, condição que frequentemente não é bem aceita socialmente, tornando-se aversiva para muitas pessoas que se encontram nessa situação. Diante das contingências impostas, Pedro cometeu o segundo crime, motivo pelo qual está preso, tendo sido condenado a 27 anos e 8 meses de reclusão por Latrocínio.

As duas respostas emitidas por Pedro são contingentes aos antecedentes apresentados anteriormente, que podem ser resumidos em condições aversivas atuando como operações estabelecedoras. Nas duas situações pode-se perceber a presença de esquemas de reforçamento concorrentes que possuíam conseqüências competitivas entre si, ou seja, conseqüências a curto prazo (reforçador positivo imediato - dinheiro) competindo com conseqüências de longo prazo (punição negativa - prisão), conforme pode ser observado na tabela 1 abaixo. Nesse caso, o reforço imediato obtido interfere, nitidamente, na manutenção do comportamento controlado pela consequência de longo prazo ${ }^{14,20}$.

Tabela 1. Contingências envolvidas nos delitos cometidos por Chico.

\begin{tabular}{|c|c|c|c|}
\hline & Antecedentes & Respostas & Consequências \\
\hline $1^{\circ}$ Delito & $\begin{array}{c}\text { - Pobreza } \\
\text { - Baixa escolaridade } \\
\text { - Ausência de rede } \\
\text { apoio socíal }\end{array}$ & $\begin{array}{l}\text { Tráfico de } \\
\text { Entorpecentes }\end{array}$ & $\begin{array}{c}\text { Estímulo Reforçador } \\
\text { Positivo } \mathrm{S}^{\mathrm{R}} \\
\text { (dinheiro) } \\
\mathrm{X} \\
\text { Punição (Prisão) }\end{array}$ \\
\hline $2^{\circ}$ Delito & $\begin{array}{l}\text { - Preconceito } \\
\text { - Privação de Dinheiro } \\
\text { - Sustentação Familiar }\end{array}$ & Latrocínio & $\begin{array}{c}\text { Estímulo Reforçador } \\
\text { Positivo } \mathrm{S}^{\mathrm{R}+} \text { (dinheiro) } \\
\mathrm{X} \\
\text { Punição (prisão) }\end{array}$ \\
\hline
\end{tabular}

Pedro passou por histórico de punições negativas (prisões anteriores) e, ainda assim, reincidiu. Notase que a punição só controlou seus comportamentos adequados enquanto o agente punidor (prisão) esteve presente. Isso denota que mesmo sob punição severa e prolongada, a frequência de resposta 
aumentará quando a punição cessar ${ }^{21}$. No entanto, na ausência do punidor e novamente exposto à privação socialmente imposta, o reforçador positivo condicionado (dinheiro) manteve seus comportamentos inadequados (atos criminais) ${ }^{4}$.

As relações interpessoais no ambiente prisional são pouco reforçadoras. Pedro relatou que evita - contato com os agentes penitenciários, pois esses também são punidores. Dentro da prisão, os agentes mantêm relação coercitiva para controlar o comportamento dos internos, conforme comentário:

"Não tem relação nenhuma. A relação que tem é bom dia, boa tarde e já é. Eu mesmo chego ali, passo bom dia, boa tarde e já fui. Eu não gosto de muita idéia comigo não, que eu não gosto de muita idéia com polícia. É o rato e o gato. Então... às vezes quando eu preciso de alguma coisa eu vou e

falo com ele."

A relação com os outros internos, também, é coercitiva e pautada pelo tipo de crime que cometeram. Quanto mais grave é o delito, maior o poder que o interno pode exercer sobre os outros. Quanto mais leve, maior o nível de coerção ao qual o detento é submetido, isto é indicado na declaração:

"a gente que tira cadeia, é muita onda que rola aqui dentro, é muita gestão, muita oprimissão [opressão]... Eu nunca fui oprimido por que no crime que eu caí é... pra eles é matador no caso, né?....Então no caso eu caí com uma morte eles aí... Mas o outro chega lá, assalto a ônibus, esses bagulho que...

155 e aí os cara sofre, né?

Pedro já cumpriv, até o momento, 17 anos de reclusão, somadas as duas condenações. Se forem adicionados também os meses em que esteve detido em delegacias, Pedro passou quase a metade de sua vida detido. Depois de tanto tempo preso, Pedro afirmou não "querer" mais cometer crimes, pois "cansou" de ficar longe dos reforçadores positivos presentes no exterior da prisão. Segundo relato do entrevistado:

"Significa está preso que eu tô perdendo tudo lá fora viu? Tudo de bom que tem lá fora eu tô perdendo. Não vou menti. Podendo curtir muito."

"Muita cadeia, 17 anos de cadeia, perdendo praia, perdendo mulher, um bocado de coisa boa lá rua hein?! (risos) Um bocado de coisa boa lá na rua e eu aqui preso..."

Para isso, ele traçou um plano de ação para ganhar dinheiro trabalhando, quando estiver em liberdade: ele pretende fazer uso do conhecimento de artesão adquirido dentro da prisão para obter seu sustento. O planejamento traçado por Pedro para se manter fora da prisão através de seu próprio trabalho denota uma variabilidade comportamental, na medida em que ao perceber que não conseguiu obter reforçadores através da prestação de serviço para outras pessoas, ele agora pretende montar o seu próprio empreendimento. Pedro fez uso de um repertório, aparentemente, adequado e adaptativo, modelado dentro da prisão por estímulos sociais. Ou seja, ele aprendeu o ofício com outros internos da penitenciária, não foi um conhecimento proporcionado pela Instituição.

Vale ressaltar que na história contingencial de Pedro, a Instituição Prisional é o agente punidor, apenas privando-o de liberdade. No entanto, para cumprir o ideal de reintegração social, a Instituição deveria aproveitar da cessação temporária da emissão de respostas delituosas como resposta à punição apresentada, para ampliar o repertório comportamental de Pedro através da apresentação de novos estímulos que pudessem evocar respostas mais adequadas. Isso ocorre, pois ao punir o indivíduo com a privação de liberdade ele pode, temporariamente, deixar $\circ$ comportamento inadequado e ter a chance de ampliar o seu repertório, ensinando-lhe formas mais adequadas de obter reforçadores e diminuindo a probabilidade de reincidência criminal ${ }^{14}$.

A maneira que a prisão teria de ensinar formas mais adequadas de obter reforçadores seria o trabalho e a educação. Nesse caso, Pedro trabalha numa fábrica de vassouras e sacolas plásticas que é uma das seis empresas existentes dentro da Instituição na qual ele está inserido. Porém, tanto o trabalho que Pedro desenvolve quanto os outros trabalhos não preparam os internos para viver em liberdade, na medida em que não são conhecimentos que possibilitem a fácil obtenção de emprego fora da cadeia. A utilização de mão de obra prisional ainda é vista, de certa maneira, como um tabu na sociedade brasileira, sendo que as experiências verificadas são esparsas e restringem-se a trabalhos de unidades de produção em prisões, geralmente em serviços de baixa qualificação ${ }^{16}$.

Dentro dessa Instituição existem algumas atividades esportivas, culturais, laborais e educacionais que 
visam melhorar a qualidade de vida e o bem-estar dos apenados. Porém, não são atividades que possibilitem uma reintegração real pela dificuldade encontrada para motivar os internos a participarem das mesmas, pelos entraves do próprio sistema prisional, político e social e pelas características específicas das atividades que são pouco eficientes à vivência externa dos apenados. Por isso, mesmo que esses projetos visem à reintegração futura, ainda são muito incipientes, não chegando a adquirir uma relevância real no processo de reabilitação da população carcerária ${ }^{15}$.

A análise funcional das contingências envolvidas na história de vida do sujeito da pesquisa foi feita a partir da identificação das possíveis variáveis controladoras do ato criminal e permite observar a presença de práticas de reintegração social, no Sistema Carcerário, pouco eficientes. Uma vez que - Pedro agregou ao seu repertório um conjunto de respostas que o permitiu, tão somente, se adaptar à realidade prisional, sem, no entanto, modelar - seu comportamento a fim de que ele pudesse emitir respostas mais desejáveis para obtenção de reforçadores. Nesse caso, parece que não tem havido um preparo real para a reinserção do indivíduo na sociedade, e a principal consequência disso é a reincidência criminal ${ }^{4}$.

\section{CONSIDERAÇÕES FINAIS}

ambiente prisional é coercitivo por natureza e, no relato de caso aqui analisado, pode-se observar que o Sistema Prisional não dispôs de meios eficazes para reabilitação do detento. Isso ocorre porque a prisão é um reflexo da sociedade, na qual muitos estão, realmente, marginalizados: sem acesso a educação de qualidade, a moradia digna, a alimentação, a princípios morais e éticos etc.

De acordo com a história de vida de Pedro e de tantos outros Pedros que se encontram todos os dias nas televisões e jornais, a maioria dos detentos nunca estiveram, de fato, inseridos na sociedade. Privados de reforçadores positivos em seus ambientes, eles buscam maneiras de satisfazer suas necessidades e acabam cometendo, desde os mais simples até os mais complexos e variados delitos.

Na prisão não são expostos a contingências que possam ampliar seus repertórios e ensiná-los a suprir suas necessidades sem que tenham que reincidir em novos delitos. A reincidência criminal, nada mais é do que o retrato de uma sociedade estigmatizadora e desestruturada e de um sistema político e social falho por utilizar métodos coercitivos para tentar manter o controle coletivo.

Torna-se necessário pensar em estratégias de investimento no tratamento penal e no acompanhamento dos egressos do sistema prisional, a fim de cumprir o que a LEP já prevê e pensar em possibilidades de construção de políticas públicas para apoio aos egressos, considerando, dentre outras medidas, a atenção psicossocial ${ }^{22}$.

\section{REFERÊNCIAS}

1. Brasil. Ministério da Justiça. Departamento Penitenciário Nacional. Levantamento nacional de informações penitenciárias Ifopen - Junho de 2014. Brasília. DF. 2014

2. Brasil. Instituto de Pesquisa Econômica Aplicada. Secretaria de Assuntos Estratégicos da Presidência da República. Reincidência Criminal no Brasil: Relatório de Pesquisa. Rio de Janeiro. Rio de Janeiro. 2015

3. Ferreira AR. Crime-prisão-liberdade-crime: 0 círculo perverso da reincidência no crime. Serviço Social e Sociedade. 2011 ; 107:509-534. doi: $10.1590 /$ S0101-66282011000300008

4. Torossian MS, Capelari A. Análise sobre reincidência criminal na abordagem comportamental. Psicólogo inFormação. 2006;10(10):102-108. doi: 10.15603/21760969/pi.v10n10p102-108

5. Mariño JMF. Análise comparativa dos efeitos da base socioeconômica, dos tipos de crime e das condições de prisão na reincidência criminal. Sociologias. 2002;8(4):220-224. doi: 10.1590/ 
6. Adorno S. A prisão sob a ótica de seus protagonistas: itinerário de uma pesquisa. Tempo Social. 1991;1(3):7-40. doi: 10.1590/ ts.v $3 \mathrm{i} 1 / 2.84813$

7. Conselho Nacional de Justiça. CNJ recomenda expansão das APACs para redução da reincidência criminal no país. Brasília: CNJ; [Internet]. 2014. Disponível em: http://www.cnj.jus.br/noticias/ cnj/28296-cnj-recomenda-expansao-das-apacspara-a-reducao-da-reincidencia-criminal-no-pais

8. Wacquant L. As prisões da miséria. la ed. Rio de Janeiro: Jorge Zahar; 1999

9. Kolker T. A atuação dos psicólogos no sistema penal. In: Gonçalves H S, Brandão E P, editores. Psicologia Jurídica no Brasil. Rio de Janeiro: Nau; 2005. P. 157-204

10. Wacquant L. Aberração carcerária à moda francesa. Revista de Ciências Sociais. 2004;47(2):215-232. doi: 10.1590/S001152582004000200001

11. Brasil. Presidência da República. Lei $n^{\circ} 7.210$, de 11 de julho de 1984. Lei de Execução Penal. Brasília. DF. 1984

12. Carvalho ACC. A educação a distância como auxílio na reintegração do indivíduo preso [Dissertação de Mestrado]. Florianópolis: UFSC; 2002. Disponível em: http://repositorio.ufsc.br/ xmlui/handle/123456789/82461

13. Martins LJ, Guilhardi HJ. História de contingências coercitivas e suas implicações: estudo de caso sob perspectiva da Terapia por Contingências de Reforçamento (TCR). In: Guilhardi HJ, Aguirre NC, editores. Sobre comportamento e cognição: expondo a variabilidade. Santo André: Esetec; 2006. P. 231-259

14. Sidman M. Coerção e suas implicações. 1 a ed. Campinas: Livro Pleno; 2001

15. Rego IP. Sociologia da Prisão. Sociedade e Estado. 2004;19(1):227-233. doi: 10.1590/ S0102-69922004000100011
16. Costa SG, Bratkowski PLS. Paradoxos do trabalho prisional na era do capitalismo flexível: o caso do DETRAN-RS. Revista de Administração Contemporânea. 2007;3(1 1):1 27-147. doi: $10.1590 /$ S $1415-65552007000300007$

17. Rangel H. Estratégias sociais e educação prisional na Europa: visão de conjunto e reflexões. Revista Brasileira de Educação. 2007;34(12):81 93. doi: $10.1590 /$ S1 413-24782007000100007

18. Brasil. Ministério da Justiça. Sistema Nacional de Informação Penitenciária (Infopen): Dados Consolidados. Brasília: Departamento Penitenciário Nacional (DEPEN). Brasília. DF. 2008

19. Boni V, Quaresma SJ. Aprendendo a entrevistar: como fazer entrevistas em ciências sociais. Revista Eletrônica dos Pós-Graduandos em Sociologia Política da UFSC. 2005;1 (2):68-80

20. Meyer S. Análise funcional do comportamento. In: Costa CE, Luzia JC, Sant'Anna HHN, editores. Primeiros passos em análise do comportamento e cognição. Santo André: Esetec; 2003. P. 75-81

21. Skinner BF. Ciência e Comportamento Humano. 11 a ed. São Paulo: Martins Fontes; 2003

22. Conselho Regional de Psicologia. Falando sério sobre prisões, prevenções e segurança pública.

Brasília: CFP; 2008 